\section{INTERCEPTED LETTER.}

“Dear Sir James, - A thousand thanks for your very satisfactory letter, and prompt attention to my wishes. Much as I feel annoyed about the puff system, and ever anxious as $I$ am to preserve the respectability and integrity of the profession, yet your position is to me particularly distressing, as I am perfectly aware that the subject of our correspondence is indebted to your persevering in. dustry and high moral feelings for the unexampled patronage which he has obtained. Before, however, I can make out his case clearly, so as to bring it before our College, it will be requisite for me to possess certain documents, which 1 request you will confer on me, as well as on the profession generally, the favour of forwarding. I want copies of any documents, or references to such authentic sources as you may be acquainted with, as will enable me to lay before the College proofs of the correctness of the line of conduct which I may feel confidence in recommending them to adopt. This will form an excellent case to bring before Mr. WArburtor, to convince him how eager the College of Physicians is to suppress quackery, regular and irregular, et cetera, et cetera, et cetera. Dr. Gardner has called upon me to consult me about the most prudent measures he could take to do away with the unfavourable impression which the puff-paragraphs have made on maxy of his friends, from his name having been so disreputably associated; and since $I$ last had the pleasure of addressing you, I have had this puff-system most severely reprimanded in the case of Lady Manners Sutron, the wife of that inestimable man, the speaker of the House of Commons. I was attending her with Mr. GuThrie, and two paragraphs, which you must have seen in the newspapers, and which, doubtless, were sent by Mr. G., purporting to be bulletins of her ladyship's illness, though, being in truth, nothing else than a part of the puff-system, were so hurtful to her ladyship's feelings, that she politely requested him to discontinue his attendance, or, in other words, to make a quiet retreat!

"You have hinted that amongst your" kind offices to Mr. Guthrie, was the employment of him to give certificates. Enough has been said on the certificate system to urge you to inform me of all particulars on this point, and I have a painful satisfaction in thinking that Sir Astrey does not stand alone as a certificate-manufacturer.

"Whenever I am favoured with the necessary credentials, I will call a special meeting in Pall Mall East, to deliberate on this unfortunate case. I have just got a hurried message to fly to Apsley House upon an election matter which interests me. So believe me in haste to be ever yours,

"H. H."

“ Dear Sir Henry,-I feel it my bounden duty to render every assistance in my power in the investigation, and $I$ send you forthwith the testimonials you require. The letter of Acres was published in an arcient volume of THE LANCET, and to this I would particularly refer the Fellows of the College. But there is one document which will be most satisfactory to the Fellows, and of which I enclose you a copy, the original of which is in the possession of the Editor of $T_{H E}$ LA NCET, to whom the communication as you will perceive, was addressed; but which he did not then publish, from the immense body of evidence which he at that time laid before the public, being sufficient, probably without it, interesting and important as it is.

"The following is the document:-

$$
\text { " " Clifton, Jan. 14th, } 1829 .
$$

" ' To the Editor of'The LA N CET. - Sir,Although I have but recently had an opportunity of perusing the whole of the documents which have been printed relative to the manner in which the business of the Westminster Eye Infirmary was conducted, I cannot even now withhold my testimony to the accuracy of the statements published in your Journal as well as to the truth of the observations you have founded upon them, and I shall be gratified by the publication of this letter in The Lancet. Having been house pupil to the institution alluded to for twelve months in the year 1821-22, and having, during that time, constantly resided in the house, 1 had ample opportunities for observing what was passing, and $I$ have no hesitation in stating that the nanner in which the business was conducted was slovenly and negligent in the extreme. Mr. Guthrie's attendance was very irregular indeed; for, although the hour of visit was ten o'clock in the morning, he used sometimes to come before that time, when there was scarcely any one there; sometimes considerably later, when most of the patients had gone home, and frequently he never came at all. I have often heard murmuring and complaint amongst the patients whilst waiting for Mr. Guthrie, and I know that many of them used to come from a great distance day after day with- 
out being able to see him at all. With regard to the "Book of Entry," I am sure it was by no mears to be relied on as presenting a true statement of the admission of the patients. It used to lie on the table, or in the drawer, which was never locked, and anybody entered, or might enter, any name he thought proper. With regard to the treatment of patients by Mr. Guthrin, I have frequently heard Dr. ForBes object to it, as being generally of too stimulating a nature. Indeed, I have often heard him say, that constitutional treatment was not in his opinion sufficiently attended to at the Eye Infirmary by Mr. Guthrie, and I remember that Dr. Fonses in his lectures used to urge this most strongly to the pupils. I have also very often heard Mr. GuTH iste's stimulating plan of proceeding condemned by those who observed the treatment at the infirmary. Indeed, I have heard the identical Mr. Thомson himself, then only a student, delivep opinions against $\mathrm{Mr}$. Guthrie's plan, and the hurried manner in which the patients were seen by Mr. G. They were admitted from the waiting room to the room wherein the remedies were employed, eight, ten, or more at a time, just as they could push themselves in when the door was opened. A table stood in the middle of the room, and upon it were generally about a dozen highly stimulating solutions, placed in a rack, within reach of Mr. GUTHRIE. A small case of ophthalmic instruments, a camel-hair brush or two, with a tolerable strong solution of the cupri sulphas in water, and some of the cupri sulphas and argenti nitras in cases, scraped to points, were ready for use. The "Book of Entry" lay upon the table, ready for any of the gentlemen present to insert the name, age, residence, and disease of the patient, together with remarks thereon, who might happen to be nearest it. Mr. Guthrie was at one end of the talle, surrounded by pupils and others, putting and ordering to be put, by one or other, no matter who, various stimulating drops into the eyes of the patients, some for acute and some for chronic inflammation, and rubbing the granulated lids of others with the cupri sulphas or argenti nitras, either in solution or otherwise, without attending much to the constitutional treatment. When a patient came to have his eyes examined, I have frequently seen Mr. Guthrie take him by the shoulder with one hand, having a bottle of drops in the other, and say "Here, putt him in a drop," without even looking at the eye. After the drop was putt in, the patient was usually sent to a sidetable to bathe his eye with warm water, and sometimes to get some pills, powders, or lotions, which were given out by a person whose name was CAmeroN, a dirty, careless fellow, who minded little or nothing whether the patient got the medicine ordered or not. Sometimes Mr. Guthrie took the trouble to write for the medicines at the back of the admissioncard, but more frequently it was a verbal order, given to myself or CAMERON, which, amidst the general disorder and confusion, was sometimes not understood, or was forgotten, and the patient got any thing or perhaps nothing.

" "With respect to the subterfuge of $\mathrm{Mr}$. G. about the house-surgeon, I send you my own certificate of attendance, filled up by Mr. GUTHRIE in his oun handwriting, and signed by himself, several days previous to its receiving Dr. For BEs's signature, in which $\mathrm{I}$ am, as I always used to be, designated "house-pupil." I never heard of a house-suryean to the institution, nor did anybody else. It is evidently an office of Mr. G.'s own creating for some purpose. The absurdity of designating any pupil who cane there for the purpose of learning his profession, house-surgeon, must be apparent to everybody, as such a name implies superior qualifications,--such as, I believe, never were possessed by any of the gentlemen living in the house, during the time they resided there. I remain, $\mathrm{Sir}$, your obedient servant,

$$
\text { " 'N. Burton." }
$$

"With regard to the certificate system, yon ought to be informed that I never employed Mr. G. to give any certificates as to character, on Sir AstuEY's principle, but only certificates to the health of invalid officers craving leave of absence from their regiments on the plea of indis. position. This appeared to me to be a feasible system, both as a preventive of insposition, and as affording me an excellent opportunity of promoting the interests of my protegé, it being generally understood that Mr. J. G. expected an adequate douceur, from the receipt of which I imagine he never finched. He made a very considerable annual sum by this new certificate system, which, I must do him the justice to say, he had the chief merit of contriving. I confess to you that I carried the system too far, by obliging many officers, who had already 'certificates' from respectable men, and under whose care they were, to go to $\mathrm{Mr}$. G. to be examined by him; and get his 'certificate,' which they of course paid for properly.

" But the system did not stop here, and I soon found out that misgivings existed, George James pretending to be connected with the Board, and insinuating 
that his certificates alone were sufficient had got his thigh fractured. From the to enable the possessor to pass the turn-i manner in which the accident occurred, pike. I found out that they were given I was apprehensive that besides this fracwith far too little inquiry as to the officers' ture, which I readily detected, there might cases; but I durst not say anything to him be some farther injury about the neck of upon the subject, he has such a spirit. the bone, and I therefore requested ProThe said system, however, has become at fessor Syme to see the boy, and give me last intolerrable; he is not contented to his opinion as to the latter point. He did give merely a 'certificate' of the officer's so, to the effect that the neck of the bone health, receive adequate remunerations, was uninjured. Once after this he again and, in many cases, attend them after- called on the boy, at my request, and wards; but he has lad the audacity to never but on these two occasions did he see dictate to me the extent of leave which the the patient. I attended the boy till the officers required.

"As you are at the head of the profession, and are looked up to by all of us for your classical learning and high moral feeling, it vould be presuming in me to attempt to point out what is the best mode of your future proceeding. It appears to me, however, that it would be most satisfactory to both colleges, and to the profession in general, to institute a court of inquiry, consisting of professional men, to be conducted upon the same principle as the milirary court inartial.

"Dear Sir HeNry, I again candidly confess to you, that he has such a spirit that I am afraid to meddle with him, and I feel, to nyy sorrow, now too late, how much I have been harasscd and conirolled by him in the management of the Board. With the greatest respect, esteem, and regard, I am, dear Sir Henry, yours,

“A. M. B. Jan. 5th, 1835. " J. M. G.

“ $P$. S. The inquiry ought to be an open one, and the gentlemen of the press have access to it. I have not the lcast objection to be called on as a witness, and Dr. Tyeodore Gornos, one of my coadjutors at the Board, can give important evidence on the occasion."

\section{UNPROFESSIONAL CONDUCr.}

\section{To the Editor of The LANCET.}

Sir,-I take the liberty of communicating to you the following particulars, arising out of a case in which, I think, I have just reason to consider myself aggrieved, and which is calculated, moreover, to injure the interests of the profession in general. It is on this latter ground alone that I have been induced to lay the circumstances before you, who have so long and so ably stood forward as the intrepid advocate of the professional community. On the 20th February last, two days after the date of the accident, $I$ was called in to see a boy, son of a Mr. Crerar, general agent, who

end of March, when he was quite recovered. On presenting my account to Crerar, the father, a small part of it was paid without any objection being made to it, but on applying some time after for payment of the remainder, he refused now on the pretext that it was overcharged. I caused him to be written to, stating my willingness to have the account referred to any of the three following gentlemen he night please to select; viz. Dr. Fairbairn, Professor Lizars, and Dr. William Campbell. He replied to my agent by letter, stating, "I shall with pleasure agree to a reference to Dr. Fairbairn, a gentleman of the highest medical eninence, on the understanding that both parties are to obtain a fair hearing, either verbally or written." Dr. Fairbairn, accordingly, having communicated with both parties, and Having heard their statements, gave the following report :-_ I have examined the above account, agreeable to the wish of Mr. Cowan and Mr. Crerar, as per their letters, and am of opinion, after taking all the circumstances into consideration, that the above accuunt is fairly charged.

(Signed) "Pever Fairbairn, M.D."

Notwithstanding this report, Crerar, in the face of his written agreement, still refused to settle the account, and I had no other resource but to summon him for payment before the Sheriff Court. He there, without being able to assign any sound reason, objected to the report of Dr. Fairbairn, and urgently proposed to the sheriff that the matter should be referred to tine decision of Mr. Syme. The sheriff agreed to remit it to that gentleman, to which $I$ at the moment formally objected, as the case had been already decided by the reference to Dr. Fairbairn, a gentleman as competent and respectable as Mr. Syme. I was at no loss, however, to comprehend the urgency of Crerar to have the case remitted to $\mathrm{Mr}$. Syme; for a few days previously he had written me a note oftering me a sum, less than onehalf of the amount of my accourt, and stating that Mr. Syme had "ordered" him to pay me this reduced sum, in full of all 